Jaana Sorvari*, Satu Rusko, Nina Jackson and Hanna-Leena Ainonen

\title{
Integrating entrepreneurial working life skills with foreign language teaching - two cases from the University of Oulu
}

\author{
https://doi.org/10.1515/cercles-2020-2033
}

\begin{abstract}
This activity report describes two cases of Language teaching for degree students in the University of Oulu with new pedagogical approaches aiming towards authentic working life skills. Co-creation, collaborative learning and cooperation across borders are the building blocks for these innovative language teaching projects. Case 1 describes Entrepreneurial Language Studies in English and Swedish courses, co-created with the Ministry of Culture and Education Key Projects, which aim for fostering entrepreneurial culture and creating entrepreneurial learning environments at universities. Case 2 is about Teaching English and Course Cooperation in English language between the students of Information Processing Science in Finland and Russia. In both of these cases, students have been challenging themselves with new ways to learn the language and at the same time acquire important skills for working life, virtual learning, presentations, communication, problem solving and business idea creation. What unites these cases is the emphasis on authentic language learning, creativity and self-efficacy. Because career paths today are increasingly complex, multidisciplinary and diverse, the ability to adapt, innovate and be flexible is vital in evolving and collaborative working environments.
\end{abstract}

Keywords: collaborative learning, teaching development, co-creation, entrepreneurial skills, transversal competencies

*Corresponding author: Jaana Sorvari, University of Oulu Languages and Communication Unit, Oulu, Finland, E-mail: jaana.sorvari@oulu.fi

Satu Rusko and Hanna-Leena Ainonen, University of Oulu Languages and Communication Unit, Oulu, Finland, E-mail: satu.rusko@oulu.fi (S. Rusko), hanna-leena.ainonen@oulu.fi (H.-

L. Ainonen)

Nina Jackson, University of Oulu, The Unit for Strategy and Science Policy, Tellus, Oulu, Finland, E-mail: nina.jackson@oulu.fi 


\section{Introduction}

This article is an activity report about the latest innovations and pedagogical approaches of the Languages and Communication Unit (LCU) of the University of Oulu (UO). Two cases will be described in this report. By means of these two cases, we can describe how our teaching curriculum has evolved through the introduction of more authentic opportunities for co-creation, interdisciplinary collaborative learning and international cooperation for both teachers and students alike. These experiences have directed our teaching methodologies towards a new vision with an understanding of unlimited possibilities by crossing borders never crossed before and deconstructing the divisions between contents and contexts that have been previously separated. We find that through collaborative co-creation between language teachers, entrepreneurship education professionals and students, an entire novel way to construct courses has been discovered.

Arene et al. (2018) has created references for the universities in Finland to promote entrepreneurial skills in the degree programs. This activity report presents Case 1, which is one of the case examples reviewed by the Finnish Education Evaluation Centre, which was one of the organizers of the seminar where the references were published. Case 2 is an innovative endeavor to integrate intercultural communication with authentic interaction between students from two countries.

The aims of this report are to describe two cases in order to inspire others to innovate language courses through co-creation and to describe the outcomes and benefits of these new methodologies.

\section{Co-creative pedagogy at the University of Oulu}

The University of Oulu is an international science university which creates innovation for the future, well-being, and knowledge through research and education. Founded in 1958, our university is one of the biggest and most multidisciplinary universities in Finland with its 13,000 students, 2,900 employees, 8 faculties and several specialized research units. Our Languages and Communication Unit offers language learning opportunities in 8 languages, including our domestic official languages Finnish and Swedish. We cooperate with our faculties and with Tellus, which is a collaboration and experimentation platform of the University of Oulu. Oulu Business School, in collaboration with Tellus, offers a variety of entrepreneurial studies including a Minor studies package in Entrepreneurship, which is available for all students. 
The aim of our language courses in the Languages and Communication Unit is mainly to teach skills and competencies for academic communication and working life. Some of these skills are problem-solving, finding new ways to operate in extended learning environments, creating business ideas and cooperating across borders. In this activity report, we present our latest innovations and pedagogical approaches in this field. In the following two cases we have increased the amount of international cooperation and developed our teaching and learning methods towards more authentic collaborative learning.

\subsection{Description of Case 1}

In the Spring term of 2019, a massive pedagogical and innovational project under the umbrella of the Ministry of Culture and Education's YTYÄ and YYTO key projects was implemented into our mandatory English and Swedish courses. This project was called Entrepreneurial language studies and its aim was to integrate Entrepreneurial pedagogics into English and Swedish language courses.

The project included over 700 students from 7 faculties, 10 teachers, 3 entrepreneurial facilitators and 3 workshops. The second phase of this project is ongoing in Autumn 2019 courses and it will continue in the Spring term of 2020. This project is designed to last, and it will remain an embedded part of our language courses and curriculum.

The Entrepreneurial language studies were born as an outcome of the project ventures and partly inspired by Wittgenstein (1922), who once said: The limits of your language are the limits of your world. The aim of our venture became to provide opportunities for students within the language courses to break their limits and extend their capacity to operate successfully in the world by enhancing courses with ever more transversal competencies and skills, namely entrepreneurial mindset and skills. Because today's career paths are more and more complex, multidisciplinary and diverse, the ability to adapt, innovate and be flexible is vital in evolving and collaborative working environments (Dufva et al. 2017). We have learned to break down the walls of course constructs to make room for the possibility to expand student potential to learn not only language and language skills, but also the competencies to think on one's feet, to co-create something from nothing and to learn how to pivot when plans and strategies fall down. And last but not least: to not fear failure, for that is part of the process of anything with a successful outcome. 


\subsubsection{Account of activity}

The goals of this project match and meet the goals of the university strategy of fostering a culture of innovation and curiosity and encouraging novel multidisciplinary solutions by providing an open, supportive environment. It also intends to simulate professional environments where dealing with ambiguity is common and the need to create something from nothing is a normal activity. For example, in order to practice creative thinking, spontaneous use of language and value creation, one task for the students was to take two random objects and bring them together to create a new product. The exercises also included problem framing, brainstorming, solution sketching by drawing, interviewing people in corridors and prototyping with Lego bricks. This kind of activity includes allowing students to collaborate and reach inwards to draw out ideas that they never even knew they had. Another aim is to facilitate interdisciplinary collaboration, which is carried out in the activities of three workshops: Creativity, Mini Design Sprint and Pitching. During the course, students took part in the three workshops and developed their ideas. The second task was to present the idea to the other students in the classroom. In this way, these workshops are integrated and embedded into the language course curriculum inspired by EntreComp: The Entrepreneurship Competence Framework (Bacigalupo et al. 2016).

The other frameworks used for pedagogical integration are embedded entrepreneurship and teaching through entrepreneurship (Franzén et al. 2019). In the context of these workshops, entrepreneurship is defined through value creation to others (Lackéus 2016).

\subsubsection{Summary of results/experience}

In contrast to traditional teaching, the new way of working was surprising for the students. Some found it demanding to find the connection between the tasks and their own learning. Most of the students were satisfied with the workshops and tasks and got new insights and inspiration. It was also good to get out of their comfort zone; that is when a person can learn the most, become more selfconfident, and develop new perspectives. Even though the meaning of the pilot included learning and improving language skills while solving problems and finding solutions, the students ended up with a great number of viable business ideas capable of filling needs that are currently unmet in society. Thus in Case 1, real innovations and solutions for working life problems, ranging from apps lowering the threshold for the reporting of bullying to gamification of the hospital school environment, were combined with the language of opinions and debates, presentations, negotiations, signposting and numerous other language functions. 
Since this was a pilot study, students contributed many ideas to develop in the workshops and the project during their respective courses. The students' wishes included becoming more proactive and forcing themselves to challenge themselves even more. It is important that teachers trust their students' ability to create new things and work self-efficiently. During the second round, the student ideas and feedback have been taken into account by increasing self-efficacy and developing the connection between the course and the workshops. This has facilitated the work of the teachers, who now, after the pilot round, are more fully aware of the working methods. Indeed, they have become more aware of the importance of fully explaining the connection between the workshops and the course content in depth. This is essential for proper embedding of the entrepreneurial mindset content into the course contents. Furthermore, it is important to embed the entrepreneurial content even further so that an explanation of the connection would not even be necessary. The entrepreneurial content would genuinely be a true part of the course. Some teachers have already succeeded in this and others are still working on it.

“As I will become a teacher, I really enjoyed all the workshops and those gave me new ideas, new approaches to my coming job! I really enjoyed the presentation workshop as I get really nervous while keeping one. Also, I liked how much we got to do and make new ideas together!"

The teachers received new inspiration and content for their teaching and many practical ideas for the further development of the content. As an example, the students in the future will be given a pre-task before the workshops so that they will bring their own prepared ideas to the workshop.

"This workshop was fabulous! It opened up new ways of seeing the world for students and teachers and also helped each person to understand that they too have full potential to be creative."

In addition to Karvi's case example (Pyykkö et al. 2020), this case has also been featured in the Finelc-newsletter (8/19 Jakkula et al. 2019).

\subsection{Description of Case 2}

"IT's MOre than teacher exchange with an Arctic Attitude; it is also a student-centered language learning experience with an innovative and entrepreneurial mindset.” ITMO Technical University is branded with the slogan "It's more than university", the University of Oulu highlighting its northern latitude with the words "Science with an arctic attitude".

Combining the slogans of both universities, this sentence pinpoints Case 2; the cooperation between the Languages and Communication Unit of the University of Oulu and ITMO Technical University in St. Petersburg. Sharing best practices, 
shadowing, interacting with the students, blogging, conferencing and innovating new cooperation prospects - these are just some examples of the cooperationrelated activities.

This case consists of two parts: teacher exchange funded by the First + program and a blogging project incorporated into the pilot course English Communication for Information Processing (ECIP) in the University of Oulu and Professional Communication in IT course in ITMO.

\subsubsection{Account of activity}

The cooperation was launched in November 2018 with a visit to Oulu by four Russian English teachers. This visit enabled both the visitors and the hosts to share and learn teaching practices and different approaches to ESP. The visit included teaching and shadowing as well as feedback and reflections on the sessions, along with fruitful meetings and discussions on both professional and other topics. Intercultural competency and a sense of global citizenship were strengthened amongst students and teachers. As teachers, Karen Niskanen and Satu Rusko learned how to create a fairer educational community by increasing respect for different languages and cultures and adapted practical ways to utilize the potential of different cultures for inspiration and problem solving; all this via discussing and addressing intercultural opportunities and challenges in hands-on lessons, discussions and meetings. In the Finnish-American-Russian teaching environment of the teacher exchange lessons, the students' intercultural awareness and curiosity were increased through cross-cultural lecture discussions and negotiation skills exercises. These skills were concretely practiced in a Trade Fair session, where students presented and commented on app ideas presented in posters in an international, real working life-like environment.

The next step was taken in April 2019, when three English teachers from the University of Oulu returned the visit to St. Petersburg. The program included teaching, shadowing, meetings, feedback and discussions, providing valuable insights into respective ESP approaches and teaching practices. The concurrent NATE Russia Convention and English Language Expo conference enabled the visitors to participate in several lectures and workshops and share the knowledge and experiences acquired.

The teacher presented two English courses given at the University of Oulu: Scientific Communication course in English (NJIT - China) and Medical English and Clinical Psychology Student Conference, both of which the conference audience regarded as highly relevant. Among several other future prospects, this visit 
sparked a blogging cooperation involving Information Processing Science students in Finland and Russia. This project forms the second part of the second case.

English Communication for Information Processing (ECIP) was a pilot course involving team teaching, working life skills, entrepreneurial aspects and a Russian flavor through blogging cooperation. Divided into Reading and Oral skills and integrated with the substance studies, the course embraced the aims of Case 1 Entrepreneurial Language Studies: transferable competences and entrepreneurial skills. The students were invited to complement their digital mindset with communicative and working-life relevant soft skills. In their group projects, they created an innovative mobile application aimed at bringing some benefit to the lives of residents and/or visitors to Oulu. These projects were presented in a Trade Fair poster session at the end of the course. In the intercultural blogging project, among other posts, the University of Oulu students shared their innovations with their Russian colleagues and vice-versa. Commenting on others' blog posts was an essential part of the blogging project. The ECIP team teachers Karen Niskanen and Satu Rusko were pleased to see that blogging proved beneficial for UO and ITMO teachers and students, allowing them to experience real authentic communication and engagement with international peers online, while practicing their writing skills at the same time. As with Case 1, the Information Processing Science cooperation between Oulu and St. Petersburg has been designed to last. Hence, it will continue with the second round in Spring 2020; moreover, it is about to be complemented with a student exchange project.

Case 2 included a second teaching visit to ITMO by the ECIP team teachers. The October visit gave both parties new professional insights. In addition to teaching, shadowing and discussions, teachers participated in the "More than ESP" conference, which was a good opportunity to hear about the research and work of many other teachers from around Russia and beyond. The Finnish ECIP teachers gave a joint conference workshop "Integrating Entrepreneurial Skills into ESP", sharing the experiences in both of the cases presented in this article. One of the highlights was meeting the ITMO blogger group and discussing their feelings about the project. The October 2019 visit to ITMO provided inspiring, new perspectives on teaching methodologies, a network of future contacts, as well as ideas and tools for working with the ever-more international student body.

\subsubsection{Summary of results/experience}

The cooperation between the University of Oulu and ITMO University has benefited us in multiple ways. It has contributed to improved teaching practices through increased cultural competency and Russian colleagues' insights e.g., into 
assessment and syllabus planning and delivery. This has had a direct effect on students' learning experiences, the joint blog project being the most tangible example. These experiences will have far-reaching positive effects on both the teachers and students of both universities, not only with their academic benefits and intercultural, innovative and working-life relevant aspects, but also by supporting connectedness and mutual understanding within each university and between them. The cooperation has resulted in realizing the aims of Case 1: going beyond our limits and extending our capacity to operate successfully by enhancing courses with increasingly transferable competences and skills, including entrepreneurial mindset. The University of Oulu students' feedback reflects these results and experiences:

"I think I gained a lot of skills which will be useful to me when I enter the working life in the future."

"What Ilearned from this course was mostly the value of good teamwork. We could come up with quick solutions on how to solve things and do good planning on the tasks we needed to accomplish."

"I think the blog assignment was beneficial towards learning new vocabulary, writing about interesting topics in English and sharing our project outcome with international colleagues. I have never written a blog before, which is why writing one was interesting, if not exciting, especially as the Russian aspect was there."

As a pilot project, student feedback throughout the ECIP course has served to guide course development for the next phase, when the course is taught again in the spring of 2020.

\section{Conclusive remarks and future prospects}

The future prospects for this pedagogical innovation are exciting. We will welcome new groups of students into this model until the end of 2020. Following that, we will create and share facilitator guides about the workshop trilogy, and we are aiming to turn the workshops from this pilot project into continuous practice at the university and to reach all students. Many course descriptions have already been revised to include the new entrepreneurial mindset and skills content and more will be revised. We believe it to be important to attempt to reach all students to help prepare them for the ever-changing, real-world working environment, where success and survival will require adaptability, flexibility and a strong selfconfidence. This project will provide the students with the potential to extend their capacity to face the future challenges in the workplace. 
We are excited about the future prospects of our cooperation with ITMO, which includes two ITMO teachers visiting the University of Oulu next spring and another round of the blogging project. Furthermore, student exchange is being planned, involving the Faculty of Information Technology and Electrical Engineering (ITEE) and hoping to increase integration of substance and language studies in an international and entrepreneurial way. Returning to the slogans of the universities, we can conclude by describing this cooperation with the "IT'sMOre than an Arctic Attitude; it's having unlimited prospects"! We hope both of these cases will inspire our colleagues to innovate language courses through co-creation.

\section{References}

Arene (The Rectors' Conference of Finnish Universities of Applied Sciences Arene); UNIFI; Suomen Yrittäjät. 2018. Yrittäjyyssuositukset korkeakouluille [Entrepreneurship recommendations for higher education institutions]. Helsinki: Arene. http://www.arene.fi/wp-content/ uploads/Raportit/2018/Yritt\%C3\%A4jyyssuositukset/Yritt\%C3\%A4jyyssuositukset\% 20korkeakouluille\%202018.pdf.

Bacigalupo, Margherita, Panagiotis Kampylis, Yves Punie \& Godelieve Van den Brande. 2016. EntreComp: The entrepreneurship competence framework. Luxembourg: Publication Office of the European Union.

Dufva, Mikko, Minna Halonen, Mika Kari, Tapio Koivisto, Raija Koivisto, \& Jouko Myllyoja. 2017. Kohti jaettua ymmärrystä työn tulevaisuudesta [Towards a common understanding of the future of work]. Helsinki: Government Office.

Franzén, Riikka, Lenita Nieminen, \& Joachim Ramström. 2019. Unintentional exposure to entrepreneurial behavior and value creation. In Paper presented at the $3 E$ conference in Gothenburg, Sweden 8.-10.5.2019. Pori: Turku School of Economics.

Jakkula, Ville, Ainonen Hanna-Leena \& Pilke Nina (eds.). 2019. FINELC Newsletter 8. FINELC. Helsinki: FINELC. https://finelc.languages.fi/wp-content/uploads/2019/06/FINELC_ newsletter_8_2019.pdf.

Lackéus, Martin. 2016. Value creation as educational practice - towards a new educational philosophy grounded in entrepreneurship? Gothenburg: Chalmers Technical University.

Pyykkö, Riitta, Mikko Tolonen, Kimmo Levä, Seija Mahlamäki-Kultanen, Marko Pantermöller, Torsten Petterson, Sini Saarinen \& Mira Huusko, et al. 2020. The evaluation of higher education in humanities. Helsinki: Finnish Education Evaluation Centre.

Wittgenstein, Ludwig. 1922. Tractatus Logico-Philosophicus. London: Harcourt, Brace and Company Inc. 